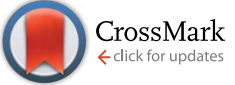

Cite this: RSC Adv., 2016, 6, 113260

\title{
Insights into the effect of surface functional groups on catalytic performance for hydrogen generation from sodium borohydride $\uparrow$
}

\author{
Xiang Feng, ${ }^{*}$ Zhaoning Song, Tongtian Guo, Rui Yang, Yibin Liu, Xiaobo Chen \\ and Chaohe Yang*
}

Sodium borohydride hydrolysis to generate hydrogen has great potential for mobile and portable applications, and designing efficient catalysts for this reaction is indispensable. In this work, the effect of surface functional groups on hydrogen generation rate (HGR) is investigated using two polystyrene resin supported Pt catalysts. The first type of resin (resin- $\mathrm{NH}$ ) contains $-\mathrm{N}\left(\mathrm{CH}_{3}\right)_{3} \mathrm{OH}$ and abundant $-\mathrm{OH}$ groups, while the other one (resin- $\mathrm{SH}$ ) contains $-\mathrm{SO}_{3} \mathrm{H}$ and less $-\mathrm{OH}$. After excluding the influences of basicity and Pt loading, it is found that the Pt/resin- $\mathrm{NH}$ catalyst exhibits a much higher HGR and lower activation energy compared with the Pt/resin-SH catalyst. Moreover, multiple techniques such as FT-IR, $X R D, T E M$ and XPS are further employed to elucidate the intrinsic mechanism. Compared with the $-\mathrm{SO}_{3} \mathrm{H}$ group, the $-\mathrm{N}\left(\mathrm{CH}_{3}\right)_{3} \mathrm{OH}$ and $-\mathrm{OH}$ groups not only facilitate Pt dispersion by enhancing metalsupport interaction but also improve the electronic conductivity during hydrolysis by forming electronenriched Pt active sites.

Received 10th October 2016 Accepted 24th October 2016

DOI: 10.1039/c6ra25016e

www.rsc.org/advances
It is noted that the hydrogen generation rate (HGR) can be significantly enhanced by using catalyst during the $\mathrm{NaBH}_{4}$ hydrolysis reaction. Therefore, extensive studies been focused on designing efficient catalyst to achieve superior catalytic performance. Various types of catalysts have been reported for this reaction. Besides acid (e.g., oxalic acid and citric acid), ${ }^{6}$ metallic salts (e.g., $\mathrm{RuCl}_{3}, \mathrm{RhCl}_{3}$ and $\left.\mathrm{PtCl}_{3}\right),{ }^{10}$ metal borides (e.g., $\mathrm{CoB}$ and $\left.\mathrm{Ni}_{x} \mathrm{~B}\right)^{1 \mathbf{1 1 2}}$ and reduced transition metals (e.g., Co and $\mathrm{Ru}){ }^{12-14}$ supported metal catalysts have attracted exclusive attention because the performance can be improved by the geometric effect (e.g. shape of metal) and/or the electronic effect (change in the electronic environment of metal). To date, a series of $\mathrm{Pt}, \mathrm{Co}, \mathrm{Ru}$ and $\mathrm{Ni}^{15-17}$ catalysts supported on carbon, ${ }^{17-20} \mathrm{Al}_{2} \mathrm{O}_{3},{ }^{21}$ polymer, ${ }^{22-26} \mathrm{SiO}_{2},{ }^{27} \mathrm{TiO}_{2},{ }^{28-30} \mathrm{ZrO}_{2}{ }^{31}$ and $\mathrm{ZrO}_{2}-\mathrm{SO}_{4}{ }^{2-32}$ have shown good performance for $\mathrm{NaBH}_{4}$ hydrolysis. Kojima et al. ${ }^{33}$ studied the effect of $\mathrm{LiCoO}_{2}$ support on catalytic performance, and attributed the high catalytic performance to the enhanced water adsorption on support which facilitates $\mathrm{H}_{2}$ formation from $\mathrm{H}_{2} \mathrm{O}$ by reduction of $\mathrm{H}^{+}$. Dong et $a .^{23}$ showed that the hydrophobicity and hydrophilicity of polymer support could tune the metal loading, and thus change the hydrogen production rate. Notably, the surface functional groups as important part of support usually have interaction with the metal nanoparticles, and thus change the catalytic performance by metal-support interaction. ${ }^{34}$ It is thus of great significance to choose suitable surface functional groups for the design of highly efficient catalyst. However, few reports have focused on the role of surface functional groups during the $\mathrm{NaBH}_{4}$ hydrolysis reaction. Therefore, understanding the 
effects of surface functional groups on HGR will undoubtedly be beneficial to improve the performance of catalyst for $\mathrm{NaBH}_{4}$ hydrolysis.

Herein, effect of surface functional groups on HGR for $\mathrm{NaBH}_{4}$ hydrolysis are elucidated using two types of polystyrene resins supported Pt catalysts. The first type of resin (resin-NH) has $-\mathrm{N}\left(\mathrm{CH}_{3}\right)_{3} \mathrm{OH}$ and abundant $-\mathrm{OH}$ groups, while the other type (resin- $\mathrm{SH}$ ) contains $-\mathrm{SO}_{3} \mathrm{H}$ and less $-\mathrm{OH}$ groups. To increase the accuracy of the comparison, the average size of the resin particles and Pt loadings are keenly controlled. As a result, the Pt/resin-NH catalyst exhibits a much higher HGR and lower activation energy compared with those of Pt/resin-SH catalyst. Furthermore, combining characterizations of FT-IR, XRD, SEM, TEM and XPS, the effects of surface functional groups on metalsupport interaction and catalytic performance are investigated. The insights reported here are of referential importance to the design and development of highly active supported metal catalysts.

\section{Experimental methods}

\subsection{Materials}

Sodium borohydride $\left(\mathrm{NaBH}_{4}, \mathrm{AR}\right)$, sodium hydroxide $(\mathrm{NaOH}$, $\mathrm{AR})$ and hexachloroplatinic acid $\left(\mathrm{H}_{2} \mathrm{PtCl}_{6}, \mathrm{AR}\right)$ were purchased from Sinopharm. $\mathrm{NaBH}_{4}$ was used as strong reducing agent and $\mathrm{H}_{2}$ source for preparation of $\mathrm{Pt}$ nanoparticles and hydrolysis reactions, respectively. Two kinds of polystyrene resin beads with different surface functional groups were purchased from yzhou water treatment technology Co., Ltd. These two kinds of polystyrene resins, i.e., resin-SH and resin-NH have abundant $-\mathrm{SO}_{3} \mathrm{H}$ and $-\mathrm{N}\left(\mathrm{CH}_{3}\right)_{3} \mathrm{OH}$ groups respectively and similar mesh size of 30-40. Deionized water was taken from a Millipore's Milli-Q ultra-purification system having resistivity greater than 18.2 $\mathrm{MW} \mathrm{cm}^{-1}$. All chemicals were used as received without further purification.

$\mathrm{Pt} /$ resin-SH and Pt/resin-NH catalysts were prepared by incipient wetness impregnation method as follows. In a typical process, $1 \mathrm{~g}$ resin beads was added in required volume of $\mathrm{H}_{2} \mathrm{PtCl}_{6}$ aqueous solution at ambient temperature, and then stirred for $30 \mathrm{~min}$. Afterwards, the reactor was placed in cooling water which was maintained at $0{ }^{\circ} \mathrm{C}$ to prevent vigorous reaction. $5 \mathrm{wt} \% \mathrm{NaBH}_{4}$ solution was then added to reduce Pt/resin catalysts under stirring. The beads produced were filtered and washed repeatedly with de-ionized water to remove by-products and residual ions. The resultant black beads were then dried under vacuum at $50{ }^{\circ} \mathrm{C}$ for $6 \mathrm{~h}$. Pt loadings of the Pt/resin-NH and $\mathrm{Pt} /$ resin-SH catalysts are $2 \mathrm{wt} \%$.

\subsection{Characterization}

X-ray diffraction (XRD) was performed on a Rigaku D/Max $2550 \mathrm{VB} / \mathrm{PC}$ diffractometer using $\mathrm{Cu} \mathrm{K}_{\alpha}$ radiation. Fourier transform infrared spectroscopy (FT-IR) was performed on a Nicolet 6700, where the samples were ground with $\mathrm{KBr}$. Transmission electron microscope (TEM) characterization was carried out for reduced and grinded catalysts on a JEOL JEM $2100 \mathrm{~F}$ with accelerating voltage of $200 \mathrm{kV}$. Metal particle sizes and distributions were determined by measuring more than 150 randomly selected Pt nanoparticles. Scanning electron microscope (SEM) of prepared catalysts was identified on a JEOL JSM6700F. Atomic absorption spectroscopy (AAS) was carried out using a ZEEnit 600 spectroscopy for elemental analysis. X-ray photoelectron spectroscopy (XPS) analysis of Pt catalyst was performed on a PHI5000Versa Probe spectrometer with monochromatic $\mathrm{Al} \mathrm{K}_{\alpha}$ radiation $(h \nu=1486.6 \mathrm{eV})$, in which the samples were stored under Ar atmosphere at room temperature before XPS analysis. The binding energy of C 1s (284.6 eV) was taken as a reference to correct the binding energy of the samples. The spectra of Pt element were curve-fitted by the software XPSPEAK 4.1 with $80 \%$ Lorentzian-20\% Gaussian peaks to determine the Pt binding energy.

\subsection{Hydrogen generation measurement}

The HGR for $\mathrm{NaBH}_{4}$ hydrolysis in alkaline solution was measured by a classic gas volumetric method. The hydrogen generation performance was tested in a $100 \mathrm{~mL}$ three-neck flask immersed in a constant temperature bath. $50 \mathrm{mg}$ catalysts were introduced into a sealed three-neck flask, and aqueous solution consisting of $\mathrm{NaBH}_{4}$ and $\mathrm{NaOH}$ was added into the flask to initiate the hydrolysis reaction under stirring. The volume of generated hydrogen was calculated according to the volume of water replaced by hydrogen. Each group of measurements was done in duplicate for at least 3 times to reduce the error as much as possible.

\section{Results and discussion}

\subsection{Effect of surface functional group on catalytic performance}

The different functional groups of two kinds of polystyrene resin are first determined by FT-IR spectra, as shown in Fig. 1. For both resins, characteristic bands of $\mathrm{C}-\mathrm{H}$ stretching and aromatic C-C stretching show up at 3000-3025 and $1470 \mathrm{~cm}^{-1}$, respectively. In addition, the adsorption bands of $\mathrm{C}-\mathrm{H}$ out-ofplane bending and aromatic $\mathrm{C}-\mathrm{C}$ out-of-plane bending are observed at ca. 750 and $700 \mathrm{~cm}^{-1}$, respectively. ${ }^{35}$ The above

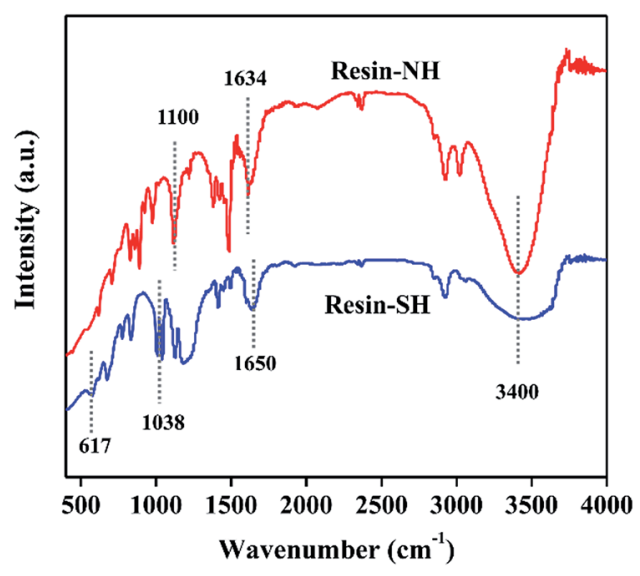

Fig. 1 FT-IR spectra of resin-NH and resin-SH samples. 
bands confirm the presence of polystyrene matrix. For resin-SH sample, characteristic bands at 617 and $1038 \mathrm{~cm}^{-1}$ are clearly observed. These adsorption bands are bending vibration of $-\mathrm{OH}$ in $-\mathrm{SO}_{3} \mathrm{H}$ and symmetric stretching vibration of $\mathrm{O}=\mathrm{S}=\mathrm{O}$, indicating the presence of $-\mathrm{SO}_{3} \mathrm{H}$ surface functional group. The band at $1650 \mathrm{~cm}^{-1}$ is $\mathrm{C}=\mathrm{C}$ extending vibration of styrene. In contrast, for resin-NH sample, the surface quaternary amine group is evidenced by the adsorption bands at 1100 and 1634 $\mathrm{cm}^{-1}$, assigning to the stretching vibration of $\mathrm{C}-\mathrm{N}$ and bending vibration of $\mathrm{N}-\mathrm{H}^{36}$ It should be noted that the strong adsorption bands at around $3400 \mathrm{~cm}^{-1}$ are surface $-\mathrm{OH}$ groups. Compared with resin-SH sample, the intensity of $-\mathrm{OH}$ band is much stronger, indicating that more $-\mathrm{OH}$ groups show up in the resin-NH sample.

Fig. 2 shows the XRD patterns of Pt/resin-SH and Pt/resin-NH samples. It is clear that all samples present two phases. The first phase, i.e., the principal component of the spectrum at $2 \theta=18$ $20^{\circ}$ is the amorphous polymeric matrix. The different diffraction peaks at $2 \theta=39.75,46.23$ and 67.51 can be indexed as (111), (200) and (220) planes respectively, corresponding to the face-centered cubic (FCC) structure of Pt nanoparticle. It is obvious that there is broadening of diffraction peak at $39.75^{\circ}$ for $\mathrm{Pt} /$ resin-NH catalyst, which suggests the decrease of Pt crystal size. ${ }^{37}$ The average crystallite grain sizes of the Pt nanoparticles are calculated according to Scherrer eqn (2):

$$
d=\frac{0.89 \lambda}{\beta_{1 / 2} \cos \theta}
$$

where $d$ is the average particle size (nm), $\lambda$ is the wavelength of the X-ray used (1.54056 $\AA$ ), $\theta$ is the angle at the maximum of the peak (rad), and $\beta_{1 / 2}$ is the width of the peak at half height in radians. The estimated Pt particle sizes of $\mathrm{Pt} / \mathrm{resin}-\mathrm{SH}$ and $\mathrm{Pt} / \mathrm{resin}-\mathrm{NH}$ catalysts are 5.8 and $4.1 \mathrm{~nm}$, respectively. In other words, the average Pt particle size of Pt/resin-NH catalyst is slightly smaller than that of Pt/resin-SH catalyst. Fig. 3(a) and (b) shows the SEM images depicting surface morphologies of the two types of resin beads. The average sizes of the two resin beads are approximate to $500 \mu \mathrm{m}$. Moreover, the surfaces of

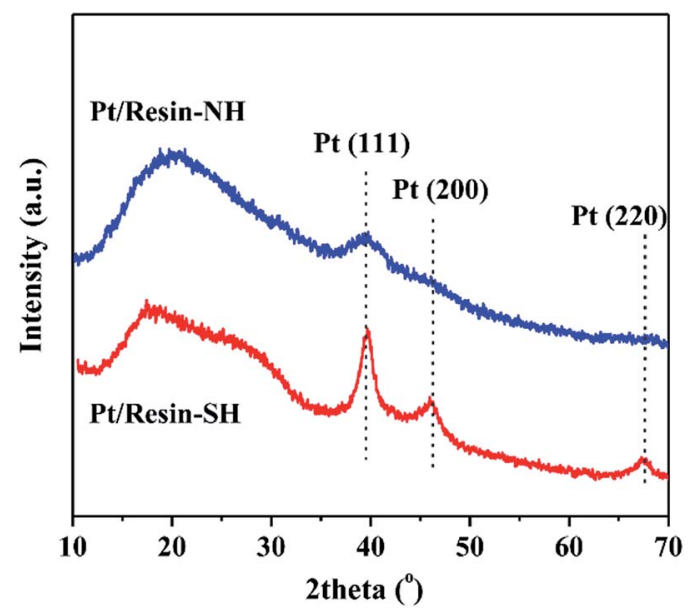

Fig. 2 XRD patterns of Pt/resin- $\mathrm{NH}$ and Pt/resin-SH catalysts. resin beads are relatively smooth. In order to gain further information about Pt particle size distribution, TEM characterization is also performed. Fig. 3(c)-(f) shows the representative TEM images of Pt/resin-SH and Pt/resin-NH samples and corresponding Pt particle size distributions. Compared with the average particle size (i.e., $4.9 \mathrm{~nm}$ ) of Pt/resin-SH catalyst, the Pt/ resin- $\mathrm{NH}$ catalyst has a slightly smaller size of $3.4 \mathrm{~nm}$. This trend is in accordance with the previous XRD results.

$\mathrm{Pt} / \mathrm{resin}-\mathrm{SH}$ and $\mathrm{Pt} / \mathrm{resin}-\mathrm{NH}$ catalysts with the same $\mathrm{Pt}$ loadings of $2 \mathrm{wt} \%$ are then tested for $\mathrm{NaBH}_{4}$ hydrolysis in order to elucidate the effect of surface functional groups on HGR. Fig. 4 shows the catalytic performance of the two catalysts. The acidic polystyrene polymer could lead to self-hydrolysis of $\mathrm{NaBH}_{4}$ to hydrogen. However, neglectable hydrogen is generated within a very short period of time when the polystyrene polymer resin-SH is added to solution. This is because $\mathrm{H}^{+}$ions left on the surface of polymer beads are completely consumed, thus stopping the hydrolysis reaction of $\mathrm{NaBH}_{4}$. The similar phenomenon is also confirmed by Chen et al. ${ }^{38}$ Clearly, the pure resin-NH and resin-SH supports all show neglectable HRG rate, excluding the influence of acidity on catalytic performance. In addition, the Pt/resin-NH catalyst exhibits much higher HGR of

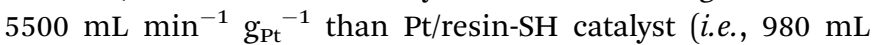
$\left.\min ^{-1} \mathrm{~g}_{\mathrm{Pt}}{ }^{-1}\right)$.

In order to further confirm the effect of surface functional group on performance, the HGR at various reaction temperature is also investigated, as shown in Fig. 5(a) and (b). For Pt/ resin-NH catalyst, the HGR increases from 5500 to $24400 \mathrm{~mL}$ $\min ^{-1} \mathrm{~g}_{\mathrm{Pt}}{ }^{-1}$ with the rise of reaction temperature from 25 to $55^{\circ} \mathrm{C}$. In comparison, the HGR only grows from 980 to $6800 \mathrm{~mL}$ $\mathrm{min}^{-1} \mathrm{~g}_{\mathrm{Pt}}{ }^{-1}$ in the same temperature range for $\mathrm{Pt} / \mathrm{resin}-\mathrm{SH}$ catalyst. This temperature dependent reaction rate can be used to evaluate the activation energy by Arrhenius eqn (3):

$$
r=r_{0} \exp \left(-\frac{E_{\mathrm{a}}}{R T}\right)
$$

where $r$ is the reaction rate $\left(\mathrm{mL} \mathrm{min}^{-1} \mathrm{~g}_{\mathrm{Cat}}{ }^{-1}\right), E_{\mathrm{a}}$ is the activation energy $\left(\mathrm{kJ} \mathrm{mol}^{-1}\right), R$ is the gas constant $\left(8.3145 \mathrm{~J} \mathrm{~mol}^{-1} \mathrm{~K}^{-1}\right)$ and $T$ is the absolute temperature (K). The calculated activation energy of Pt/resin-NH and Pt/resin-SH catalysts are 40.99 and $64.27 \mathrm{~kJ} \mathrm{~mol}^{-1}$, respectively. The lower activation energy of Pt/ resin-NH confirms the conclusion that the hydrolysis reaction is more easily to take place on $\mathrm{Pt} /$ resin catalyst with $-\mathrm{N}\left(\mathrm{CH}_{3}\right)_{3} \mathrm{OH}$ than with $-\mathrm{SO}_{3} \mathrm{H}$ group.

It should be noted that pure resin-SH and resin-NH supports show neglectable $\mathrm{H}_{2}$ generation rate, nevertheless, Pt/resin catalysts with same Pt loadings and preparation parameters (e.g., preparation and drying temperature, mixing time and charging sequence ${ }^{39,40}$ ) but different surface functional groups exhibit quite different performance. Therefore, the catalytic performance of Pt catalysts should be originated from distinct metal-support interaction which is mainly affected by the different surface properties of polymer supports. Firstly, it is noted from Fig. 3 that Pt/resin catalyst with keenly controlled preparation parameters exhibit slightly different Pt nanoparticle sizes. From the perspective of geometric effect, the slightly different Pt nanoparticle sizes could contribute to the 

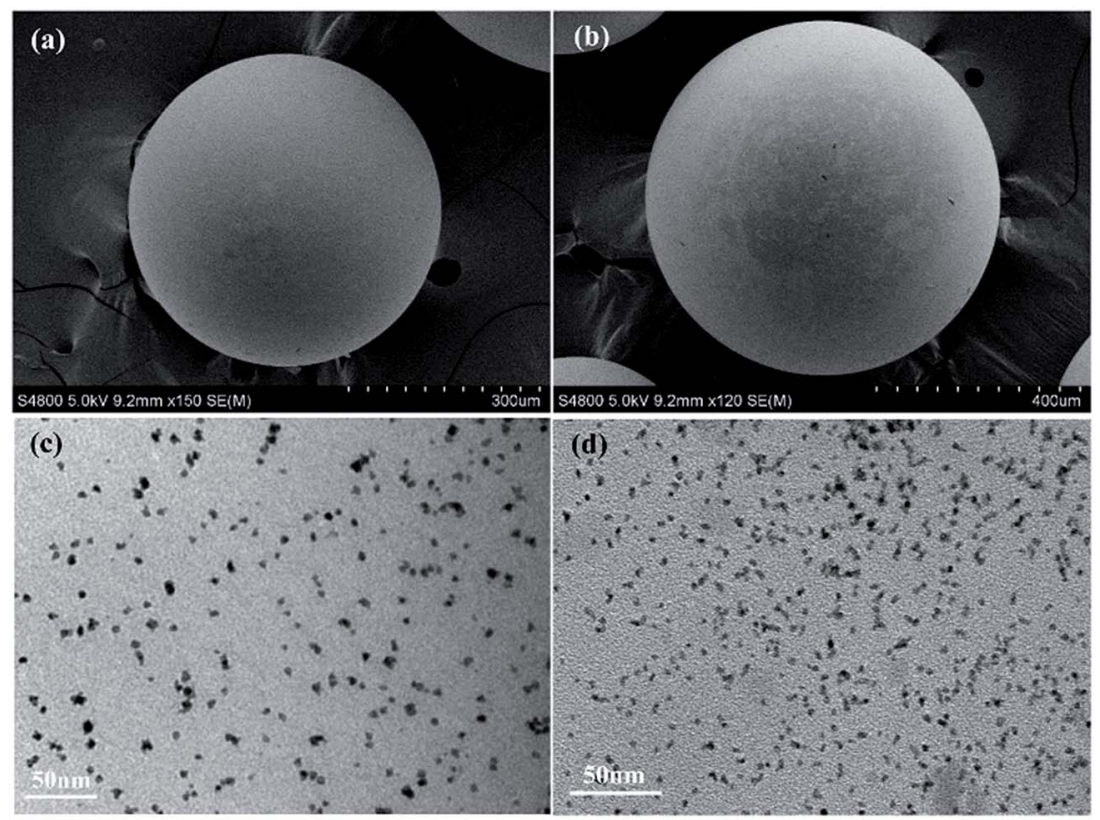

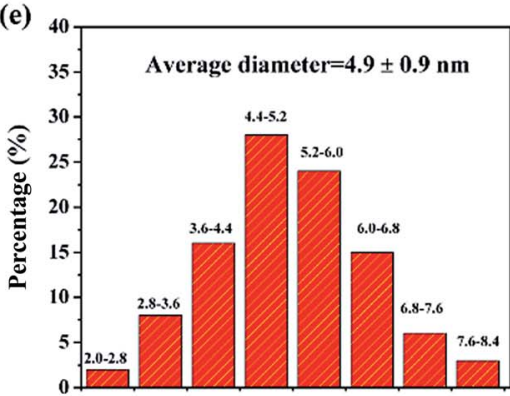

Particle size $(\mathrm{nm})$ (f)

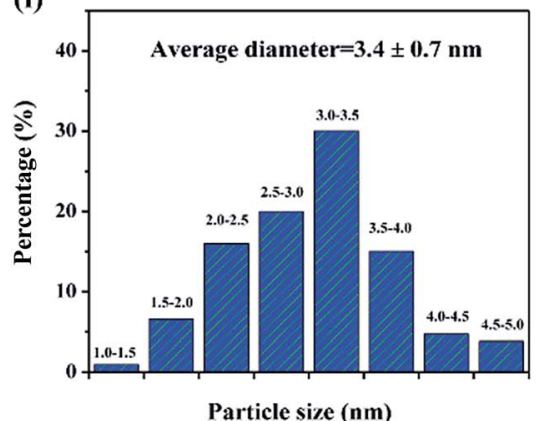

Fig. 3 SEM images of resin-SH (a) and resin- $\mathrm{NH}$ (b); representative TEM images and corresponding particle size distributions of Pt/resin-SH (c and e) and Pt/resin- $\mathrm{NH}$ ( $d$ and f). The scale bars in (c and d) represent $50 \mathrm{~nm}$.

distinct catalytic performance since Kojima ${ }^{33}$ founded that as the crystallite size of Pt decreases, the HGR increases. The surface acidic oxygen surface groups on resin-SH could be

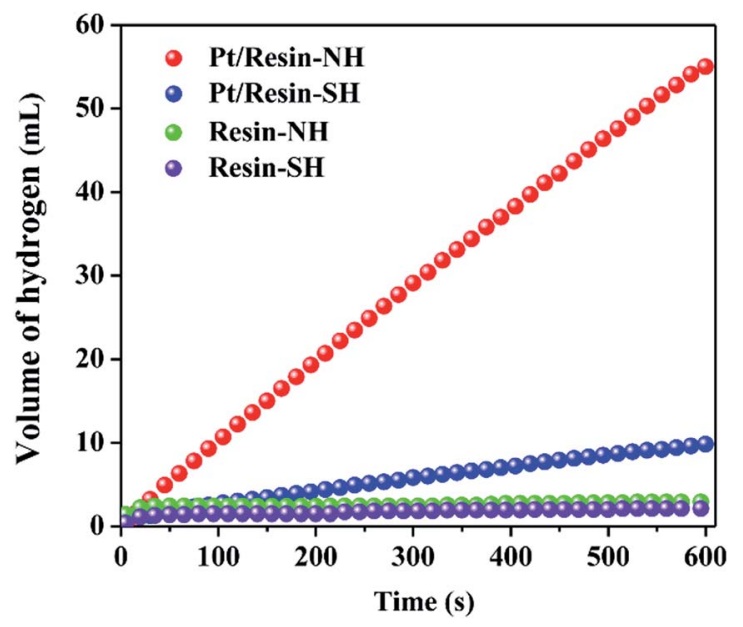

Fig. 4 Effects of surface functional group on hydrogen generation performance in $0.5 \mathrm{~mol} \mathrm{~L}^{-1} \mathrm{NaBH}_{4}$ solution containing $0.5 \mathrm{~mol} \mathrm{~L}^{-1}$ $\mathrm{NaOH}$ at $25^{\circ} \mathrm{C}$. considered as weak anchoring sites ${ }^{41}$ On resin- $\mathrm{NH}$, the basic $\mathrm{N}$-functionality with moderate strength could also show strong interaction with $\mathrm{H}_{2} \mathrm{PtCl}_{6}$ during impregnation and act as the anchoring site for the hexachloroplatinic anion. ${ }^{42,43}$ In addition, during the preparation process of $\mathrm{Pt} / \mathrm{resin}-\mathrm{NH}$ catalyst, part of $-\mathrm{N}\left(\mathrm{CH}_{3}\right)_{3} \mathrm{OH}$ can exist as $-\mathrm{N}\left(\mathrm{CH}_{3}\right)_{3}{ }^{+}$which may also interact with hexachloroplatinic anion, ${ }^{38}$ favoring the Pt dispersion on the resin surface. This result is also in consistent with the previous finding that surface functionalization of the support could affect the Pt dispersion by strong metal-support interaction. ${ }^{44}$ Moreover, the presence of abundant oxygen containing groups (i.e., $-\mathrm{OH}$ ) on resin- $\mathrm{NH}$ can enhance the hydrophilicity of the support and thus facilitate the stabilization of the Pt NPs, resulting in a better dispersion. ${ }^{45}$ This should be one main effect of surface functional group on catalytic performance.

Besides the geometric effect, the role of surface functional groups is also investigated from the perspective of electronic effect by XPS characterizations. Fig. 6 shows the corresponding $\mathrm{X}$-ray photoelectron spectra. Comparing the binding energy of pure Pt $(71.2 \mathrm{eV})^{46}$ with that of metallic Pt on resin-NH support $(70.8 \mathrm{eV})$, there is a negative shift of $0.4 \mathrm{eV}$. This is mainly caused by the strong metal-support interactions which results 

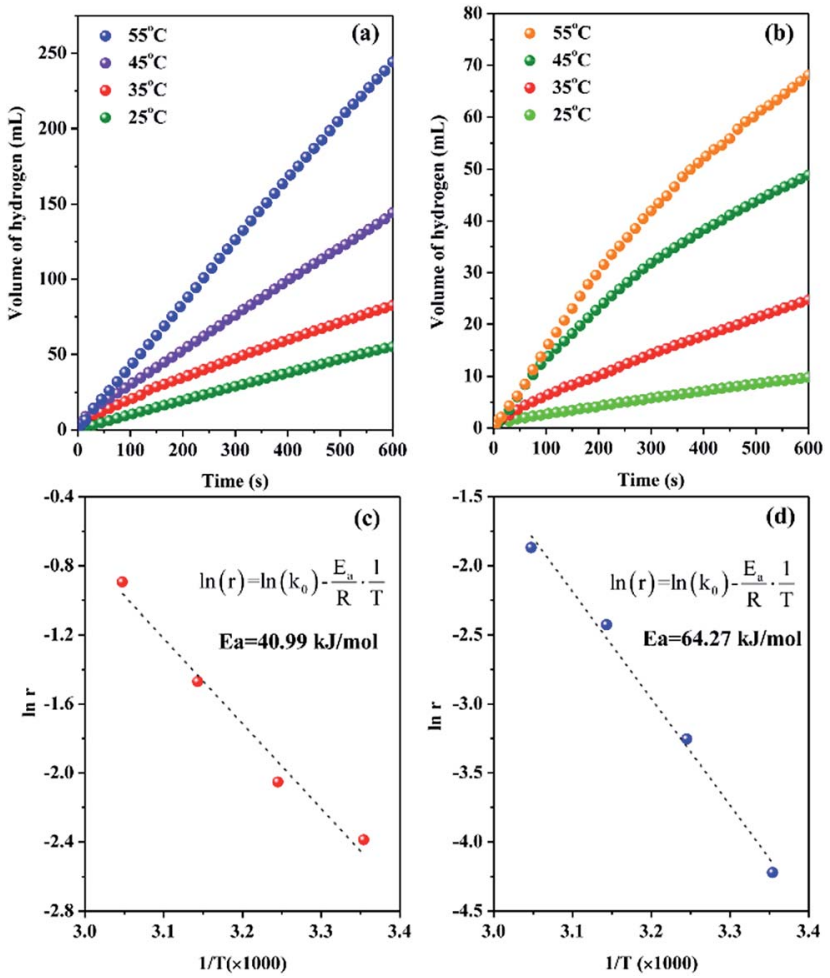

Fig. 5 Hydrogen generation performance at different temperature and activation energy on $\mathrm{Pt} /$ resin- $\mathrm{NH}$ ( $\mathrm{a}$ and $\mathrm{c}$ ) and $\mathrm{Pt} / \mathrm{resin}-\mathrm{SH}$ ( $\mathrm{b}$ and d) catalysts.
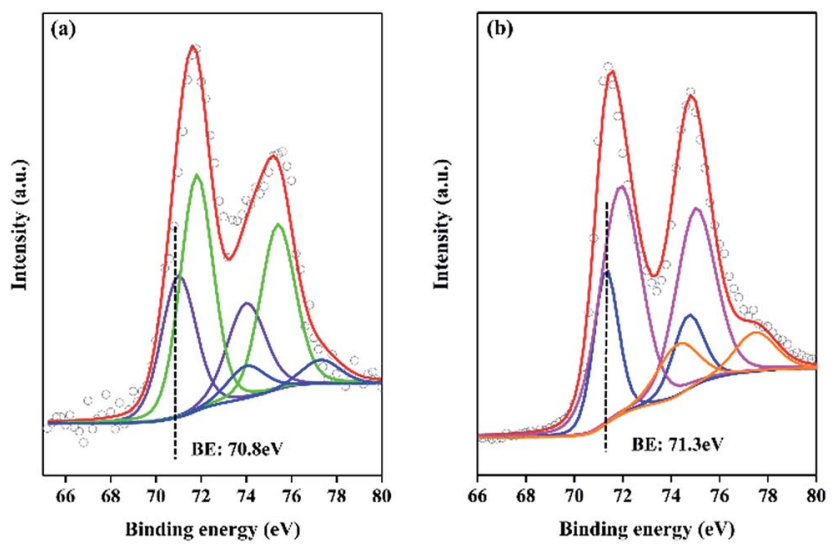

Fig. 6 X-ray photoelectron spectra of Pt 4 f levels for Pt/resin- $\mathrm{NH}$ (a) and $\mathrm{Pt} /$ resin-SH (b) catalysts.

in electron transfer from the support to Pt, leading to a decrease in d-band vacancy. ${ }^{47}$ Moreover, compared with the binding energy of Pt/resin-SH catalyst $(71.3 \mathrm{eV})$, a negative shift of Pt $4 \mathrm{f}_{7 / 2}$ binding energy of $\mathrm{Pt} / \mathrm{resin}-\mathrm{NH}$ catalyst is also observed. In other words, the metallic Pt NPs supported on resin-NH has much lower binding energy than that on resin-SH. This negative shift of Pt binding energy makes Pt as electron-enriched metal active sites, which could facilitate the electronic conductivity during hydrolysis reaction by providing hydrogen in hydridic form, which then leaves the metal sites and reacts with a $\mathrm{H}_{2} \mathrm{O}$ molecule to produce $\mathrm{H}_{2}$ and $\mathrm{OH}$ ion. ${ }^{48}$ This should be another effect of surface functional group on the catalytic performance.

\subsection{Influence of $\mathrm{NaOH}$ concentration}

In general, $\mathrm{NaOH}$ is added to the solution of $\mathrm{NaBH}_{4}$ as the stabilizer in order to keep the $\mathrm{NaBH}_{4}$ solution stable at the room temperature. However, the concentration of $\mathrm{NaOH}$ greatly affects the catalytic performance. Fig. 7 shows the influence of $\mathrm{NaOH}$ concentration on catalytic performance. With the increase of $\mathrm{NaOH}$ concentration from 0.25 to $4 \mathrm{~mol} \mathrm{~L}^{-1}$, the HGR decreases from 8100 to $1699 \mathrm{~mL} \mathrm{~min}^{-1} \mathrm{~g}_{\mathrm{Pt}}{ }^{-1}$. The negative effect of $\mathrm{NaOH}$ concentration agrees with the results in literature. ${ }^{49}$ This is mainly because there are three main steps in the hydrolysis of $\mathrm{NaBH}_{4}$ on the catalyst surface such as $\mathrm{NaBH}_{4}$ adsorption, $\mathrm{NaBH}_{4}$ hydrolysis and $\mathrm{H}_{2}$ desorption from the catalyst surface. The adsorption of $\mathrm{BH}_{4}{ }^{-}$on the catalyst surface is reported to be the rate-determining step. ${ }^{50}$ Therefore, the increase in the concentrate of $\mathrm{OH}^{-}$would increase the alkalinity and viscosity of the solution. The $\mathrm{OH}^{-}$may adsorb competitively with $\mathrm{BH}_{4}{ }^{-}$on the catalyst surface, resulting in the decrease in the reaction rate. The above result that HGR decreases with the increase of $\mathrm{NaOH}$ concentration together with the neglectable HGR of the pure resin catalyst (Fig. 4) demonstrate that the higher catalytic performance of Pt/resin$\mathrm{NH}$ catalyst is not due to the higher basicity of resin- $\mathrm{NH}$ support.

To sum up, the reason for the higher performance of resin$\mathrm{NH}$ supported Pt catalyst should be mainly due to the different metal-support interaction which are affected by surface functional groups. On the one hand, the presence of $-\mathrm{N}\left(\mathrm{CH}_{3}\right)_{3} \mathrm{OH}$ and abundant $-\mathrm{OH}$ groups facilitate the dispersion of Pt nanoparticles, resulting in slightly smaller Pt nanoparticles which are more active towards $\mathrm{NaBH}_{4}$ hydrolysis. On the other hand, the presence of $-\mathrm{N}\left(\mathrm{CH}_{3}\right)_{3} \mathrm{OH}$ and abundant $-\mathrm{OH}$ groups results in a negative shift of Pt binding energy, which leads to the formation of electron-enriched Pt active sites and favors the electronic conductivity during hydrolysis reaction

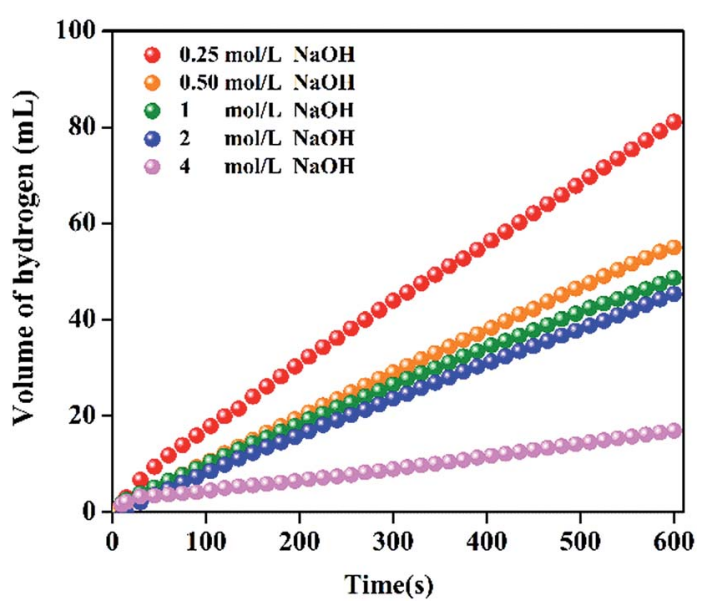

Fig. 7 Hydrogen generation performance at different concentration of $\mathrm{NaOH}$ ranging from 0.25 to $4 \mathrm{~mol} \mathrm{~L}^{-1}$ for $\mathrm{Pt} /$ resin- $\mathrm{NH}$ catalyst. 


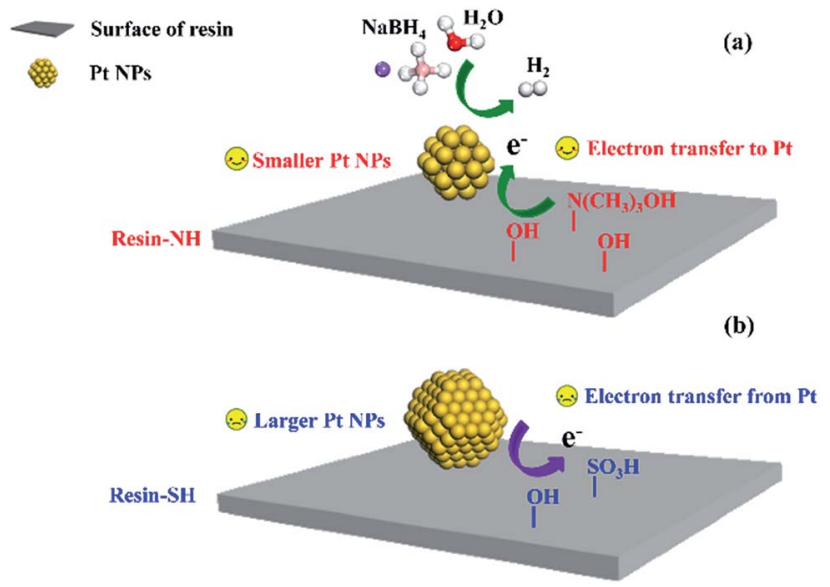

Fig. $8 \mathrm{NaBH}_{4}$ hydrolysis over Pt/resin- $\mathrm{NH}$ (a) and Pt/resin-SH (b) catalysts with different surface functional groups.

(Fig. 8). Table $\mathrm{S} 1 \uparrow$ shows the catalytic performance of reported catalysts ${ }^{51-55}$ for $\mathrm{NaBH}_{4}$ hydrolysis. It can also be seen that compared with other efficient catalysts, the Pt/resin-NH catalyst also exhibit good performance due to the presence of unique surface functional groups. Although bimetallic Pt-Ru/LiCoO shows higher HGR, the monometallic Pt/resin-NH catalyst still shows promising performance since it can be further improved by adding another metallic promoter. More importantly, these results provided in this work offer a new direction of designing more effective supported metal catalysts for $\mathrm{NaBH}_{4}$ hydrolysis by manipulating surface functional groups of support. Further enhancing the catalytic activity of supported metal catalysts on other materials such as carbon using the strategy in this work is also an interesting topic and will be carried out in our future study.

\section{Conclusions}

In this work, effect of surface functional groups on HGR for $\mathrm{NaBH}_{4}$ hydrolysis are elucidated using two kinds of polystyrene resin supported $\mathrm{Pt}$ catalysts, i.e., resin- $\mathrm{NH}$ containing $-\mathrm{N}\left(\mathrm{CH}_{3}\right)_{3} \mathrm{OH}$ and abundant - $\mathrm{OH}$ groups and resin-SH containing $-\mathrm{SO}_{3} \mathrm{H}$ and less $-\mathrm{OH}$ groups. By excluding the effect of basicity and Pt loadings on catalytic performance, it is found that the Pt/resin-NH catalyst exhibits a much higher HGR (5500 $\mathrm{mL} \min ^{-1} \mathrm{~g}_{\mathrm{Pt}}{ }^{-1}$ ) than $\mathrm{Pt} /$ resin-SH catalyst (980 $\mathrm{mL} \mathrm{min}^{-1} \mathrm{~g}_{\mathrm{Pt}}{ }^{-1}$ ) at room temperature. This is also confirmed by a lower activation energy of Pt/resin-NH (40.99 $\mathrm{kJ} \mathrm{mol}^{-1}$ ) than that of $\mathrm{Pt} / \mathrm{resin}^{-}$ $\mathrm{SH}$ catalyst $\left(64.27 \mathrm{~kJ} \mathrm{~mol}^{-1}\right)$. Compared with the average nanoparticle size of $\mathrm{Pt} /$ resin-SH catalyst $(4.9 \mathrm{~nm}$ ), that of $\mathrm{Pt} /$ resin- $\mathrm{NH}$ catalyst is slightly smaller $(3.4 \mathrm{~nm})$. In addition, compared with the binding energy of $\mathrm{Pt} / \mathrm{resin}-\mathrm{SH}$ catalyst $(71.3 \mathrm{eV})$, a negative shift of $\mathrm{Pt} 4 \mathrm{f}_{7 / 2}$ binding energy of $\mathrm{Pt} /$ resin-NH catalyst is also observed. Consequently, the surface functional groups on resin$\mathrm{NH}$ not only facilitate the dispersion of Pt on support which results in smaller-sized Pt nanoparticles, but also reduces Pt binding energy which leads to the formation of electronenriched Pt active sites and better electronic conductivity.

\section{Acknowledgements}

This work is financially supported by the Natural Science Foundation of China (21606254), Natural Science Foundation of Shandong Province (ZR2016BB16), Special Grade of the China Postdoctoral Science Foundation (2016T90657) and postdoctoral innovation project of Shandong (201601011).

\section{Notes and references}

1 U. B. Demirci, O. Akdim, J. Andrieux, J. Hannauer, R. Chamoun and P. Miele, Fuel Cells, 2010, 10, 335.

2 Y. Chen, L. Liu, Y. Wang and H. Kim, Fuel Process. Technol., 2011, 92, 1368.

3 A. Pinto, M. Ferreira, V. Fernandes and C. Rangel, Catal. Today, 2011, 170, 40.

4 L. Schlapbach and A. Züttel, Nature, 2001, 414, 353.

5 W. Chen, J. Ji, X. Duan, G. Qian, P. Li, X. Zhou, D. Chen and W. Yuan, Chem. Commun., 2014, 50, 2142.

6 H. Schlesinger, H. C. Brown, A. Finholt, J. R. Gilbreath, H. R. Hoekstra and E. K. Hyde, J. Am. Chem. Soc., 1953, 75, 215.

7 D. Hua, Y. Hanxi, A. Xinping and C. Chuansin, Int. J. Hydrogen Energy, 2003, 28, 1095.

$8 \mathrm{~J}$. Ingersoll, N. Mani, J. Thenmozhiyal and A. Muthaiah, J. Power Sources, 2007, 173, 450.

9 S. C. Amendola, S. L. Sharp-Goldman, M. S. Janjua, N. C. Spencer, M. T. Kelly, P. J. Petillo and M. Binder, Int. J. Hydrogen Energy, 2000, 25, 969.

10 H. C. Brown and C. A. Brown, J. Am. Chem. Soc., 1962, 84, 1493.

11 S. Jeong, R. Kim, E. Cho, H. J. Kim, S. W. Nam, I. H. Oh, S. A. Hong and S. H. Kim, J. Power Sources, 2005, 144, 129.

12 J. C. Walter, A. Zurawski, D. Montgomery, M. Thornburg and S. Revankar, J. Power Sources, 2008, 179, 335.

13 B. H. Liu, Z. P. Li and S. Suda, J. Alloys Compd., 2006, 415, 288.

14 S. C. Amendola, S. L. Sharp-Goldman, M. S. Janjua, M. T. Kelly, P. J. Petillo and M. Binder, J. Power Sources, 2000, 85, 186.

15 P. Krishnan, T. H. Yang, W. Y. Lee and C. S. Kim, J. Power Sources, 2005, 143, 17.

16 D. Xu, H. Zhang and W. Ye, Catal. Commun., 2007, 8, 1767. 17 C. Wu, H. Zhang and B. Yi, Catal. Today, 2004, 93, 477.

18 A. Boran, S. Erkan, S. Ozkar and I. Eroglu, Int. J. Energy Res., 2013, 37, 443.

19 X. Zhang, Z. Wei, Q. Guo and H. Tian, J. Power Sources, 2013, 231, 190.

20 Y. Li, Q. Zhang, N. Zhang, L. Zhu, J. Zheng and B. H. Chen, Int. J. Hydrogen Energy, 2013, 38, 13360.

21 Z. Li, H. Li, L. Wang, T. Liu, T. Zhang, G. Wang and G. Xie, Int. J. Hydrogen Energy, 2014, 39, 14935.

22 H. Cai, L. Liu, Q. Chen, P. Lu and J. Dong, Energy, 2016, 99, 129.

23 H. Cai, P. Lu and J. Dong, Fuel, 2016, 166, 297.

24 A. D. Chowdhury, N. Agnihotri and A. De, Chem. Eng. J., 2015, 264, 531. 
25 M. Dinç, Ö. Metin and S. Özkar, Catal. Today, 2012, 183, 10. 26 F. Li, E. E. Arthur, D. La, Q. Li and H. Kim, Energy, 2014, 71, 32.

27 Y. J. Shih, C. C. Su, Y. H. Huang and M. C. Lu, Energy, 2013, 54, 263.

28 A. H. Tamboli, A. A. Chaugule, F. A. Sheikh, W. J. Chung and H. Kim, Energy, 2015, 89, 568.

29 E. Petit, P. Miele and U. B. Demirci, ChemSusChem, 2016, 9(14), 1777-1780.

30 Ö. Şahin, M. S. İzgi, E. Onat and C. Saka, Int. J. Hydrogen Energy, 2016, 41, 2539.

31 U. Demirci and F. Garin, J. Mol. Catal. A: Chem., 2008, 279, 57.

32 U. Demirci and F. Garin, Catal. Commun., 2008, 9, 1167.

33 Y. Kojima, K.-I. Suzuki, K. Fukumoto, M. Sasaki, T. Yamamoto, Y. Kawai and H. Hayashi, Int. J. Hydrogen Energy, 2002, 27, 1029.

34 W. Chen, J. Ji, X. Feng, X. Duan, G. Qian, P. Li, X. Zhou, D. Chen and W. Yuan, J. Am. Chem. Soc., 2014, 136, 16736.

35 I. Jang, J. Sung, H. Choi and I. Chin, J. Mater. Sci., 2005, 40, 3021.

36 S.-H. Lim and S. M. Hudson, Carbohydr. Res., 2004, 339, 313. 37 K. Takemura, J. Appl. Phys., 2001, 89, 662.

38 C. H. Liu, B. H. Chen, C. L. Hsueh, J.-R. Ku, M.-S. Jeng and F. Tsau, Int. J. Hydrogen Energy, 2009, 34, 2153.

39 X. Feng, X. Duan, H. Cheng, G. Qian, D. Chen, W. Yuan and X. Zhou, J. Catal., 2015, 325, 128.

40 X. Feng, Y. Liu, Y. Li, C. Yang, Z. Zhang, X. Duan, X. Zhou and D. Chen, AIChE J., 2016, 62(11), 3963-3972.
41 K. E. Swider and D. R. Rolison, Electrochem. Solid-State Lett., 2000, 3, 4.

42 F. Su, Z. Tian, C. K. Poh, Z. Wang, S. H. Lim, Z. Liu and J. Lin, Chem. Mater., 2009, 22, 832.

43 B. P. Vinayan, R. Nagar, N. Rajalakshmi and S. Ramaprabhu, Adv. Funct. Mater., 2012, 22, 3519.

44 T. Maiyalagan, Appl. Catal., B, 2008, 80, 286.

45 X. Li, G. Fan and C. Zeng, Int. J. Hydrogen Energy, 2014, 39, 14927.

46 J. Contour, G. Mouvier, M. Hoogewys and C. Leclere, J. Catal., 1977, 48, 217.

47 N. G. Akalework, C. J. Pan, W. N. Su, J. Rick, M. C. Tsai, J. F. Lee, J. M. Lin, L. D. Tsai and B. J. Hwang, J. Mater. Chem., 2012, 22, 20977.

48 R. Pena-Alonso, A. Sicurelli, E. Callone, G. Carturan and R. Raj, J. Power Sources, 2007, 165, 315.

49 Y. Shang, R. Chen and G. Jiang, Int. J. Hydrogen Energy, 2008, 33, 6719.

50 J. Zhang, W. Delgass, T. Fisher and J. Gore, J. Power Sources, 2007, 164, 772.

51 N. Sahiner, T. Turhan and L. A. Lyon, Energy, 2014, 66, 256.

52 T. Turhan, Y. A. Güvenilir and N. Sahiner, Energy, 2013, 55, 511.

53 S. Yildiz, N. Aktas and N. Sahiner, Int. J. Hydrogen Energy, 2014, 39, 14690.

54 N. Sahiner, S. Yildiz and H. A. Lohedan, Appl. Catal., B, 2015, 166-167, 145.

55 P. Krishnan, K. L. Hsueh and S. D. Yim, Appl. Catal., B, 2007, 77, 206. 